\title{
Application of Fuzzy Controller for Two-Leg Inverter Solar PV Grid Connected Systems with High Voltage Gain Boost Converter
}

\author{
CH Hussaian Basha* and C. Rani \\ School of Electrical Engineering, VIT University, Vellore, India
}

Received 21 June 2020; Accepted 24 March 2021

\begin{abstract}
At present, the three-phase Voltage Source Inverters (VSI's) are playing a major role in Photovoltaic (PV) grid-connected systems. The drawbacks of conventional VSI's are high implementation complexity, high power loss and less reliable. In order to overcome the drawbacks of conventional VSI's, in this article, a fuzzy logic PWM controller-based two-leg three phase Voltage Source Inverter (VSI) is proposed to extract the maximum power of solar PV and to maintain constant grid voltage and frequency as it is having wide input and output operation and multiple fast controlling actions. The Low Pass Filter (LPF) based small-signal model slider Pulse Width Modulation (PWM) controller is used in Inductor Coupled Boost Converter (ICBC) to improve system dynamic response, voltage gain and infinite switching at different solar irradiation conditions. An adaptive Maximum Power Point Tracking (MPPT) technique is used to track the fast change of solar irradiations. The voltage at the DC-link capacitor and grid voltage are analyzed at different irradiation conditions.
\end{abstract}

Keywords: Duty cycle, fuzzy logic controller, SSICBC, small-signal model slider controller, two-leg three-phase inverter

\section{Introduction}

Out of all the renewable energy sources, solar PV (Photovoltaic) technology is one of the most powerful solutions to generate electricity from renewable energy sources. This technology has several advantages such as noise-free, less environmental pollution, no movable parts and easy implementation [1]. The drawback of solar power generation is installation cost. However, the installation cost of PV can be reduced by improving the efficiency of solar power generation and enhancing the manufacturing technology.

It has been noticed that over the past decade the PV power generation keeps on increasing. PV power is mainly used in batteries, fuel cells, hybrid electric vehicles, automotive systems, and headlamps, etc [2]. The interfacing of PV sources with the converter is one of the challenging tasks in PV power generation [3]. The PV power is used mostly in grid-connected systems and it is considered as a quick-rising section due to the lack of firewood power and ecological pollution [4].

From the literature survey [1-5], the per-unit electricity generation cost of PV power systems is high. In order to reduce the cost of solar power generation, a dc-dc converter is interfaced in between the PV system load. From the literature survey [6], there are different types of dc-dc converters are used to step up the PV voltage which is $\mathrm{CBC}$, CIBC, and SEPIC etc. However, the drawbacks of conventional boost converters are less static voltage gain and high implementation complexity. In order to overcome the drawbacks of conventional boost converters, in this article, a single switch coupled inductor boost converter is used to step up the PV voltage. The voltage of PV mainly depends on the coupled inductor turns. The attractive features of the proposed boost converter are high voltage gain, continuous

*E-mail address: Sbasha238@gmail.com

ISSN: 1791-2377 @ 2021 School of Science, IHU. All rights reserved.

doi:10.25103/jestr.142.02 output current and fewer ripples in converter output voltage [7].

The solar PV gives nonlinear I-V and P-V characteristics. As a result, it is difficult to transform the maximum power from the source to load. From the literature survey [8], there are different types of MPPT techniques are used to track the MPP. The most commonly used conventional MPPT techniques are: Perturb and Observe (P\&O) [9], Hill Climb (HC) [10], and Incremental Conductance (IC) [11] which are used for low and medium power applications where the accuracy of MPP tracking is not needed. In P\&O [9], the MPP tracking has been done by comparing instantaneous power $\left(\mathrm{P}_{\text {instant }}\right)$ with the previous power $\left(\mathrm{P}_{\text {previous }}\right)$. If the comparative results give the positive sign, it perturbs in the same direction otherwise perturbs in the negative direction. The major drawback of the P\&O technique is high steady-state oscillation across MPP. In order to overcome this issue, an adaptive $\mathrm{P} \& \mathrm{O}$ algorithm is used in article [12] to reduce the oscillations across MPP. In addition, a PI controller is included in $\mathrm{P} \& \mathrm{O}$ to reduce the ripple content in PV voltage thereby improving the steadystate response of $\mathrm{PV}$ at different irradiation and temperature conditions. However, this method has the drawback of less MPP tracking efficiency.

In article [10], the HC MPPT technique is used to track MPP in which the variation of duty cycle with respect to the PV power $(d P / d D)$ is zero. If the change of power $d P>0$, then the duty of boost converter is increased in order to achieve the $d D>0$. If power $d P<0$, then the duty of boost converter is reduced in order to achieve the $d D<0$. In this way, the duty cycle of the boost converter is adjusted by comparing the instantaneous power with the previous power. The major drawback of the HC method is less accuracy in MPP tracking at the rapid change of atmospheric conditions.

The drawbacks of the HC technique can be confronted by using the IC MPPT technique [11]. This technique operates based on the slope of I-V and P-V characteristics of the solar 
PV. The slope of the P-V curve is zero when the operating point of PV reaches the MPP. The slope of the P-V curve is positive when the operating point of $\mathrm{PV}$ is on the left side of MPP otherwise it is negative. The disadvantage of the IC MPPT technique is less MPP tracking speed at dynamic irradiation conditions of solar PV. In order to overcome the drawbacks of conventional MPPT techniques, in this article, an adaptive MPPT technique is used to track the MPP with high speed.

From the literature survey [13], there are different types of PWM techniques are used in PV fed grid-connected systems to generate the switching pulses to the inverter. The Sine PWM technique is used in article [14] in order to reduce the switching power losses and maintaining the constant grid voltage. The SVPWM is used in article [15] to reduce the ripple content in the output voltage with a high modulation index. From the proper selection of switching angles, the lower order harmonics of the inverter output voltage is eliminated by using a Neural Network based PWM technique [16]. The drawback of the NN technique is required for high training time. In order to overcome the drawbacks of the above PWM techniques, in this article, a fuzzy logic PWM controller-based PWM technique is used in two-leg VSI to maintain the load voltage constant with unity power factor.

\section{Proposed system description}

In this article, a two-stage power conversion interface between solar PV and grid and it is used in low, medium and high-power applications is shown in Fig. 1. In this circuit, the PV panel consists of multiple arrays that are connected in series. This series connection gives a high voltage for PV grid-connected applications [2]. The circuit in Fig.1 is designed with two converter steps. The first step is nonisolated ICBC for high voltage gain with increased performance and the second level is a two-leg three-phase inverter for converting $\mathrm{DC}$ to $\mathrm{AC}$. Here, the power decoupling between the dc-dc converter and inverter has been stretched by using the coupling capacitors $C_{d 1}$ and $C_{d 2}$. In addition, these capacitors are used to store electrical energy. The system load in each individual phase, by absolute current generation as Ipa, Ipb, and Ipc. Grid side inductors $\left(L_{t f}\right)$ and resistors $\left(R_{t f}\right)$ are used to indicate the three-phase transformer and that transformer is interfaced in between the inverter and grid. It also provides an enhanced improvement in grid power quality. In order to achieve higher efficiency from the solar $\mathrm{PV}$, it is essential to maintain the balance between PV array and load, so that the operational point of PV coincides with the MPP [17].

In this work, an adaptive MPPT method technique is considered for improving the system stability and to harvest the maximum power of solar PV. This technique gives better dynamic behavior of the system and also improves the phase shifting of the system signal. This technique is used to track the fast change of solar irradiations. The major focus is on an efficient LPF based small-signal model slider PWM controller for SSICBC and a fuzzy logic-based PWM controller for a two-leg three-phase inverter.

The small-signal model slider PWM technique is used when the system is in dynamic operation and it is required for an infinite switching sliding control [1]. The slider control is one of the most useful approaches and flexible PWM controller for the operation of higher-order nonlinear systems during unreliable operating conditions. The slider control in Fig. 1 is used to stabilize the solar panel output voltage. The purpose of this controller is to eliminate voltage ripples across PV terminals. In the second stage, the main objective is to add a fuzzy PWM controller for inverter operation. This method possesses a lot of advantages such as less implementation cost, controlling an extensive range of operations, less mathematical modeling, reducing THD of inverter output voltage and a very fast system controlling action.

The midpoint of the dc-link capacitors $\left(C_{d 1}-C_{d 2}\right)$ acts as a neutral point. The fuzzy controller is used to balance the neutral point from different uncertainties (different sun irradiation and temperature conditions). The proper design of two-leg inverter gives the load power with unity power factor, sinusoidal currents, constant grid voltage, and less THD. The three-phase output voltages and currents of the inverter are controlled by the use of open delta connection of load across the grid.

The article is structured as follows. The "design of a single diode PV equivalent circuit" is explained in SectionIII. Section-IV gives the control and design of slider controller-based ICBC. In Section-V, the design of two leg inverter is explained. In Section-VI, MATLAB-simulation results are presented and finally, conclusions are presented in Section-VII.

\section{Design of solar photovoltaic module}

In this PV module, the solar cells are designed by using monocrystalline silicon material. The combination of cells forms a module and these modules are combined to form an array. The series connection of arrays leads to the generation of a string and all these strings combine together to form the PV panel. Based on the type of PV module used, the real power output of PV is measured as watt-peak (Wp). The PV panel shows nonlinear characteristics of P-V and I-V [18]. The solar power generation depends mainly on solar module operating temperature, sun irradiations and voltages. The basic single diode model of PV-cell is shown in Fig.2.

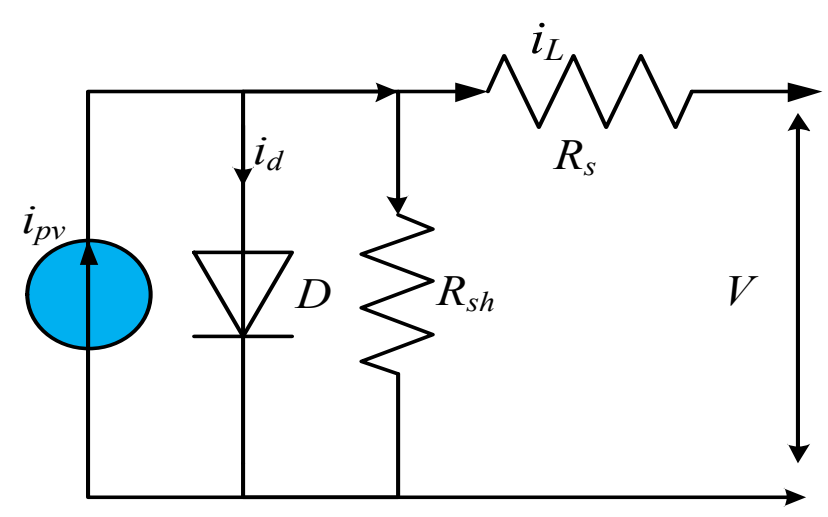

Fig.2. Mathematical model of single PV module

The basic factors considered to design a solar PV are irradiations $1000 \mathrm{~W} / \mathrm{m}^{2}$, air mass of 1.5 and solar panel junction temperature $25^{\circ} \mathrm{C}$ at benchmark test conditions determine the nominal power of solar PV [19]. For designing a solar panel, a basic single diode model solar PV is considered with five general parameters expressed as, solar cell current $\left(i_{p v}\right)$, diode diffusion current $\left(i_{0}\right)$, air mass $(a)$, series resistance $\left(R_{s}\right)$ and parallel resistance $\left(R_{s h}\right)$. The $\mathrm{PV}$ output current is given as, 


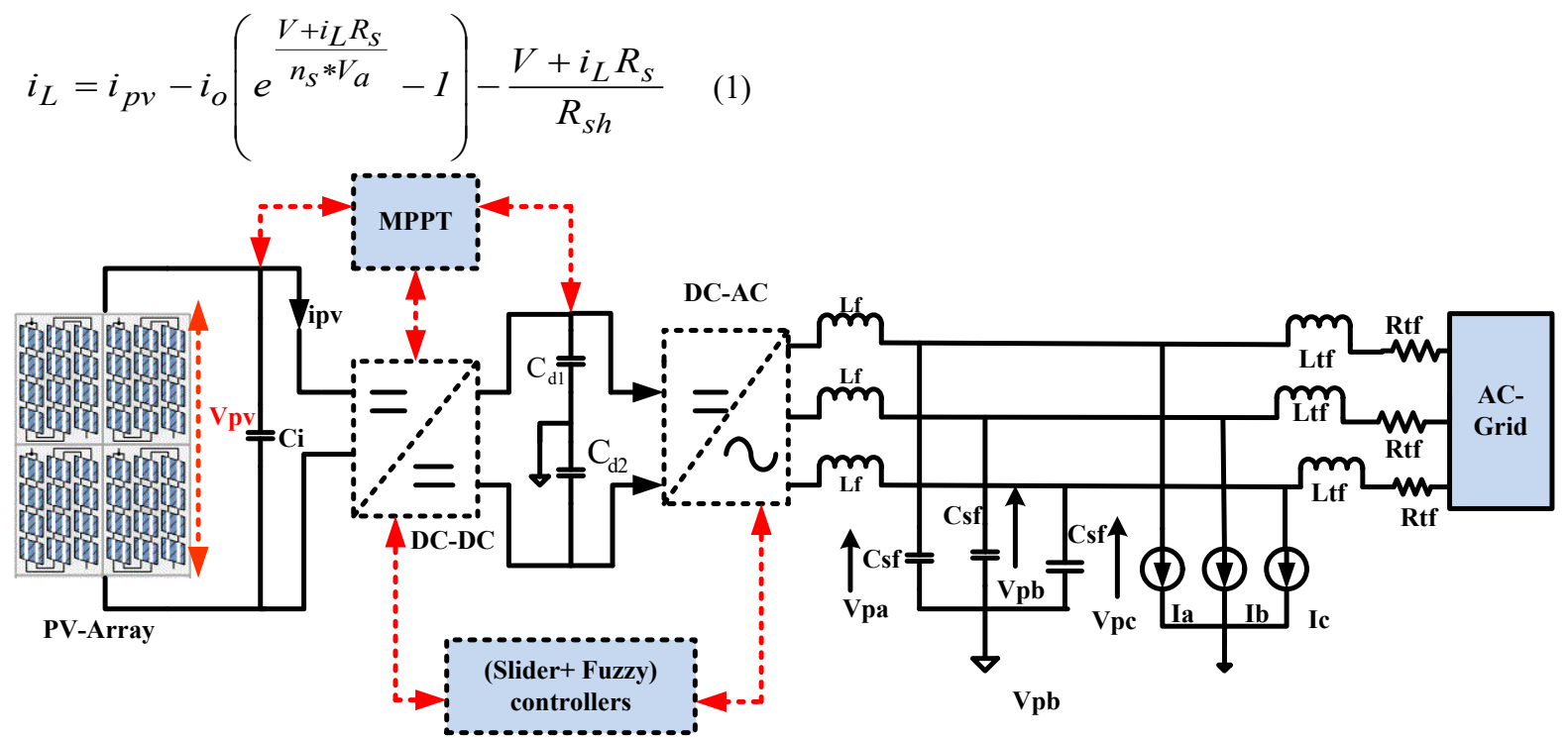

Fig. 1. Two stages of power conversion: (a). ICBC DC-DC converter. (b). Two- legs three-phase inverter (basic operation) [1]

Where,

$$
V_{a}=\frac{A k t_{s t c}}{q}
$$

Where $V_{a}$ is the thermal voltage, $t_{s t c}$ is the junction temperature at STC, $n_{s}$ is the number of series cells and $A$ is the diode quality factor. The solar panel design parameters are given in Table.1. Based on Eq.1, the short circuit current $\left(i_{s c}\right)$, MPPT current $\left(I_{M P P T}\right)$ and open circuit current $\left(i_{O C}\right)$ are derived as [1],

$$
\begin{gathered}
i_{S C}=i_{p v}-i_{O} *\left(e^{\frac{i_{S c} R_{S}}{n_{S} * V_{a}}}\right)-\frac{i_{S c} R_{S}}{R_{S h}} \\
I_{M P P T}=i_{p v}-i_{0} *\left(e^{\frac{V_{M P P T}+I_{M P P T} R_{S}}{n_{s} * V_{a}}}\right)-\frac{V_{M P P T}+I_{M P P T} R_{S}}{R_{s h}}
\end{gathered}
$$

$$
i_{o c}=0=i_{p v}-i_{o}\left(e^{\frac{V_{o c}}{n_{s} * V_{a}}}-1\right)-\frac{V_{o c}}{R_{s h}}
$$

From the P-V characteristics of the PV panel, at the maximum power point, the differentiation of $\mathrm{PV}$ power with respect to the PV voltage is zero.

$$
\left(\frac{d p_{p v}}{d v}\right)_{V=V_{M P P T}}=0
$$

Based on I-V characteristics, the short-circuited shunt resistance is calculated as shown in Eq.7.

$$
\left(\frac{d I}{d v}\right)_{I=i_{s c}}=-\frac{1}{R_{s h o}}
$$

Where $R_{\text {sho }}$ is the output short-circuited shunt resistance. From $i_{s c}$ and $V_{o c}$, the PV panel current is calculated as,

$$
i_{p v}=i_{o}\left(e^{\frac{V_{o c}}{n_{S} * V_{a}}}\right)+\frac{V_{o c}}{R_{s h}}
$$

By substituting Eq.8 in 3, the short circuit current is calculated as,

$$
i_{S c}=i_{o}\left(e^{\frac{V_{o c}}{n_{S} * V_{a}}}-e^{\frac{i_{S c} R_{S}}{n_{S} * V_{t}}}\right)+\frac{V_{o c}-i_{S c} R_{S}}{R_{s h}}
$$

From Eq.9, the approximated short circuit current is expressed as in Eq.10,

$i_{s c}=i_{o}\left(e^{\frac{V_{o c}}{n_{S} * V_{a}}}\right)+\frac{V_{o c}-i_{s} R_{s}}{R_{s h}}$

Based on the above equations, diode saturation current is derived in terms of $V_{o c}$ and $i_{s c}$.

$i_{o}=\left(i_{s c}-\frac{V_{o c}-i_{S c} * R_{S}}{R_{s h}}\right) * e^{\left(\frac{-V_{o c}}{n_{S} * V_{a}}\right)}$

By substituting equations (11) and (8) in (4), the maximum peak current is expressed as.

$I_{M P P T}=i_{s c}-I_{x}-I_{y} * e^{I_{z}}$

Where,

$$
\begin{aligned}
& I_{x}=\frac{V_{M P P T}+I_{M P P T} R_{s}-i_{s c} R_{s}}{R_{s h}} \\
& I_{y}=i_{s c}-\frac{V_{o c}-i_{s c} R_{s}}{R_{s h}}
\end{aligned}
$$




$$
I_{z}=\frac{V_{M P P T}+I_{M P P T} R_{S}-V_{o c}}{n_{S} * V_{a}}
$$

Table 1. Solar panel data and the designed parameters

\begin{tabular}{|c|c|c|c|}
\hline Parameters & symbol & Value & S.I. Units \\
\hline \multicolumn{4}{|l|}{ Panel data at the standard test condition } \\
\hline $\begin{array}{l}\text { - } \text { Panel temperature } \\
\text { - } \text { Air mass } \\
\text { - } \text { Irradiance }\end{array}$ & $\begin{array}{l}T \\
A \\
I_{i}\end{array}$ & $\begin{array}{l}25 \\
1.5 \\
500 \\
\end{array}$ & $\begin{array}{c}{ }^{0} \mathrm{C} \\
\mathrm{W} / \mathrm{m}^{2}\end{array}$ \\
\hline \multicolumn{4}{|l|}{ Designed parameters } \\
\hline $\begin{array}{l}\text { - } \text { Maximum peak power } \\
\text { - } \text { Open circuit voltage } \\
\text { - } \text { Maximum peak voltage } \\
\text { - } \text { Temperature coefficient of PV-panel at } \mathrm{V}_{\mathrm{oc}} \\
\text { - No of parallel strings } \\
\text { - } \text { No of series-connected cells per string } \\
\text { - Short circuit current } \\
\text { - } \quad \text { Maximum peak current } \\
\text { - } \text { Temperature coefficient at short circuit current } \\
\text { - } \text { Solar panel current } \\
\text { - } \text { Diode diffusion current } \\
\text { - Shunt connected resistance } \\
\text { - Series resistance }\end{array}$ & $\begin{array}{c}P_{M P P T} \\
V_{o c} \\
V_{M P P T} \\
K_{v} \\
N_{p} \\
n_{S} \\
i_{s c} \\
I_{M P P T} \\
K_{I} \\
i_{L} \\
i_{0} \\
\\
R_{S h} \\
R_{S}\end{array}$ & $\begin{array}{c}5.18178 \\
497.38 \\
402.00 \\
-0.355 \\
2 \\
24 \\
14.05 \\
12.89 \\
0.06 \\
8.8455 \\
2.27 * 10^{-10} \\
0.97625 \\
86.8053 \\
0.27328\end{array}$ & $\begin{array}{c}\mathrm{kW} \\
\mathrm{V} \\
\mathrm{V} \\
\text { \%per }{ }^{0} \mathrm{C} \\
- \\
- \\
\mathrm{A} \\
\mathrm{A} \\
\text { \%per }{ }^{0} \mathrm{C} \\
\mathrm{A} \\
\mathrm{A} \\
\\
\mathrm{Ohm} \\
\mathrm{Ohm}\end{array}$ \\
\hline
\end{tabular}

\section{Operation of capacitor clamp inductor coupled boost converter}

Basically, a conventional DC-DC boost converter is used for low, medium voltage and high-power applications. The circuit diagram of ICBC is shown in Fig.3.

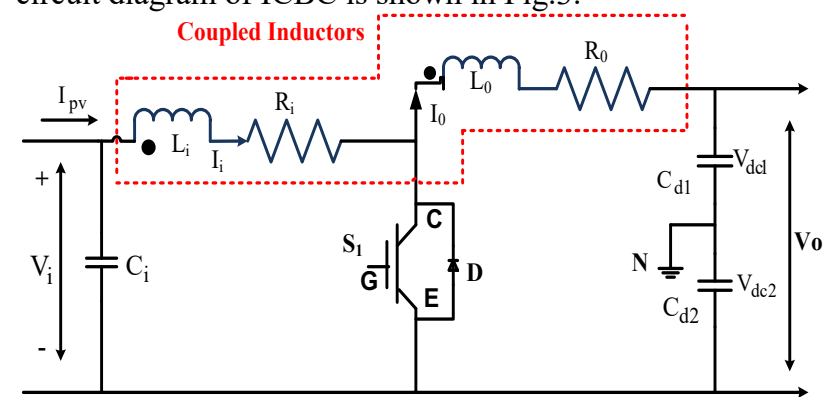

Fig. 3. Capacitor clamp inductor coupled boost converter

This converter gives better steady-state and dynamic behavior as compared to other converters with a very low voltage stress on the switch. Moreover, it is used for improving the voltage gain as compared to other nonisolated converters for PV grid-connected applications [1]. The switch ' $\mathrm{S}_{1}$ ' is the Insulated Gate Bipolar Transistor (IGBT) which is generally used for high power applications and a body diode is used to control reverse recovery voltage across the switch. The main features of this converter are less electromagnetic interference, more flexibility, enhanced efficiency, and reduced switching power losses. The voltage gain is derived from input and output loops of the DC-DC converter. The voltage gain of the boost converter is as follows,
$\frac{V_{0}}{V_{i}}=\frac{1+N_{t r} D}{D}$

Where $N_{t r}=N_{2} / N_{l}$ is the coupled inductors turns ratio. $N_{l}$ and $N_{2}$ are the primary and secondary inductors winding turns respectively.

The coupled inductor technique is one of the upcoming technique to step up the PV voltage for many applications, such as signal processing, central processing unit. In this article, a boost converter is used for improving the voltage gain by the use of coupled inductor and it gives good steadystate and transient performance [1]. Coupled inductor minimizes the circuit structure and optimizes the faster transient response for the medium and high voltage of PV grid-connected applications [20].

The primary, secondary and total inductors are derived as,

$$
\begin{aligned}
& L_{i}=\frac{L_{t}}{\left(1+N^{2}\right)} \\
& L_{0}=\frac{N^{2}}{1+N^{2}} * L_{t}=N^{2} L_{i}
\end{aligned}
$$

Where, $L_{i}, L_{o}$ and $L_{t}$ are the primary, secondary and total inductance respectively. The primary, secondary and total winding resistances $R_{i}, R_{o}$ and $R_{t}$ are given as,

$$
R_{i}=\frac{R_{t}}{1+N}
$$




$$
R_{0}=\left(\frac{N}{1+N}\right) * R_{t}
$$

The design parameters of ICBC and VSI are mentioned in Table 2.

Table 2. Converter and inverter design parameters

\begin{tabular}{lc}
\hline Parameters & Values \\
\hline$R_{I}$ & $23.85 \mathrm{~m} \Omega$ \\
$C_{d 2}$ & $10.00 \mathrm{mF}$ \\
$C_{i}$ & $10.00 \mathrm{mF}$ \\
$L_{2}$ & $14.04 \mathrm{mH}$ \\
$C_{d l}$ & $10.00 \mathrm{mF}$ \\
$L_{1}$ & $15.60 \mathrm{mH}$ \\
$R_{2}$ & $71.25 \mathrm{~m} \Omega$ \\
$R_{t f}$ & $0.267 \Omega$ \\
$L_{t f}$ & $12.00 \mathrm{mH}$ \\
$C_{f t}$ & $0.600 \mathrm{mF}$ \\
$C_{s f}$ & $0.500 \mathrm{mF}$ \\
\hline
\end{tabular}

\subsection{Small signal model slider controller}

In conventional DC-DC converter operation, sensing of the source signals for all state parameters is not mandatory for the generation of PWM pulse. Basically, error signals are enough to control the DC-DC converter and are generated by high pass filtering of the state parameters. Furthermore, a direct current component of these state parameters is altered by converter input and output voltage signals balance condition [1], [7]. The main drawback of this high pass filter-based slider controller is that it increases the system order, which effects the dynamic behavior of the system. The proposed small-signal LPF based slider controller is applied to control the ICBC. The main intention of this technique is to control the nonlinear behavior, wide input and output voltage, load imbalance, maintaining stability constant at any operating condition and improving system dynamic response. The LPF is reduced the THD of the converter output voltage.

The initial step of designing SSICBC is to select the state variables and the indirect measurement of magnetic flux which is shown in the below equation,

$$
I_{a}=\left\{\begin{array}{cc}
I_{i} & t \in T_{\text {on }} \\
I_{i} *(1+N) & t \in T_{\text {off }}
\end{array}\right.
$$

Where, the switch "ON" time $T_{o n}=D T$, switch "OFF" time $T_{\text {off }}=(1-D) T$, the total operating time of switch $T=T_{o n}+T_{\text {off }}$ and $N$ is the winding turns ratio. In equation (21), $\mathrm{I}_{\mathrm{i}}$ and $I_{a}$ are the primary and magnetizing inductor currents. By differentiating the above equation (21), the differentiation of magnetizing and output voltages are as follows,

$$
\begin{aligned}
& \frac{d I_{a}}{d t}=\frac{V_{i}-i_{a} R_{a}}{L_{i}}+\left[\left(\frac{V_{i}-V_{0}}{L_{i}(1+N)} *(1-u)\right)\right]-I_{k} \\
& I_{k}=\left[\left(\frac{R_{i}+R_{o}}{L_{i} *(1+N)^{2}} * i_{a}\right) *(1-u)\right] \\
& \frac{d V_{0}}{d t}=\left[\left(\frac{i_{a}}{(1+N) * C_{i}}\right) *(1-u)\right]-\frac{i_{0}}{C_{i}}
\end{aligned}
$$

Where, $u \in\{0,1\}$

$$
\text { If } \begin{aligned}
u & =1, \text { IGBT is ON } \\
& =0, \text { IGBT is OFF }
\end{aligned}
$$

The vector " $\mathrm{X}$ " of state parameters errors is mentioned as follows,

$$
X=\left[x_{1}, x_{2}\right]=\left\lfloor i_{a}-I_{a}^{r e f}, v_{0}-V_{0}^{r e f}\right\rfloor
$$

The mathematical standard design equation is as follows,

$$
\dot{X}=a X+b u+a z+f
$$

Where,

$a=\left[\begin{array}{cc}-\frac{\left(R_{i}+R_{0}\right)}{L_{i} *(1+N)^{2}} & \frac{-1}{L_{i} *(1+N)} \\ \frac{1}{C_{i} *(1+N)} & 0\end{array}\right], f=\left[\begin{array}{c}\frac{V_{i}}{L_{i} *(1+N)} \\ \frac{-i_{0}}{C_{i}}\end{array}\right]$

$$
b=\frac{V_{i}}{L_{i}}-\frac{R_{i} * i_{a}}{L_{i}}-\left(\frac{V_{i}-V_{o}}{L_{i} *(1+N)}\right)+V_{e}+V_{f}
$$

$V_{e}=\frac{R_{i}+R_{o}}{L_{i} *(1+N)^{2}} * i_{a}$

$$
V_{f}=\frac{i_{a}}{C *(1+N)}
$$

The reference value of the duty cycle for SSICBC is calculated as,

$$
D=\left(\frac{1-\frac{V_{i}}{V_{O}}}{1+\frac{N V_{i}}{V_{O}}}\right)
$$

Based on the variable structure theory, a sliding face is needed to consider within the state parameter region, where the control parameters are discontinuous. The sliding surface is given by equation (32),

$$
S(x)=\beta_{1} x_{1}+\beta_{2} x_{2}=\beta^{T} X: \text { where, } \beta^{T}=\left[\begin{array}{ll}
\beta_{1} & \beta_{2}
\end{array}\right]
$$

From the above condition, the sliding surface requires the state trajectories nearer the surface directed towards the sliding surfaces and the mathematical surface conditions are calculated as,

$$
\left\{\begin{array}{lll}
S(x)<0 & \text { if } & S(x)>0 \\
S(x)>0 & \text { if } & S(x)<0
\end{array}\right.
$$

In order to conclude, the circuit state surface closes by the sliding face, a particular switch action is required to design a control law to move forward. The system condition to run in the sliding mode in infinite time is given by, 
$u=\left\{\begin{array}{lll}0 & \text { if } & S(x)>0 \\ 1 & \text { if } & S(x)<0\end{array}\right.$

From Eq's.25, 32 and 23, the existing conditions are written as,

$$
\begin{aligned}
& \lambda_{1}(X)=\beta^{T} a X+\beta^{T} G<0, \text { ifS }(x)>0 \\
& \lambda_{2}(X)=\beta^{T} a X+\beta^{T} b+\beta^{T} G<0, \text { ifS }(x)<0
\end{aligned}
$$

Where,

$$
G=a z+f
$$

Where $\lambda_{1}(x) \& \lambda_{2}(x)$ are two lines in the phase plane.

The equation (34) is satisfied with the sliding surface $\mathrm{S}(\mathrm{x})=0$, hence the state trajectories start from a central point on the sliding region and it converges to the sliding surface. The state trajectories once reach the sliding surface; the existence condition includes the origin point. Hence the system operates with high stability. Basically, the slider is operating at an infinite switching frequency condition. Hence the state trajectories direction is towards the slider surface and it moves along the sliding surface. In case the slider is operating at a finite switching frequency, it necessary to apply a control law for the sliding surface. The control law is taken from [1].

$u=\left\{\begin{array}{lll}0 & \text { if } & S(x)>\Delta \\ 1 & \text { if } & S(x)<\Delta\end{array}\right.$

Where $\Delta$ an arbitrary positive value. The design parameters of the slider controller are selected to track the MPPT point at different irradiation conditions $(1000,750$ and $500 \mathrm{~W} / \mathrm{m}^{2}$ ) and it is mentioned in Table.3.

\subsection{Adaptive MPPT algorithm}

For a successful controller operation, it is necessary to run solar PV at MPPT as described in Section-II. The main problems in solar power generation are non-linear I-V and P$\mathrm{V}$ characteristics. To overcome this non-linear behavior, an adaptive MPPT technique is used [21]. This technique is widely applied for the fast-tracking of solar irradiations. The MPPT controller technique is shown in Fig.4 and it consists of low pass filter with cut off frequency $\omega_{L}$, a demodulator $\phi_{\mathrm{d}}=1$, an integrator gain $\left(K_{i}=5.4\right)$ and a lead compensator $A(s)$. In this controller, an adaptive MPPT and LPF with lead compensator is considered.

The combination of LPF and the integrator is an ultimate solution to eliminate high-frequency noise component from multidimensional signals that are associated with providing the gradient value [1]. Finally, the resultant signal is added with a small signal sine wave to determine the MPPT point. The main aim of the MPPT technique is to get the maximum power in the PV-DC link to change the P-V and I-V characteristics of the solar module.

The MPPT controller reference voltage $\mathrm{V}_{\text {MPT Tref }}$ is fed to a slider controller to give an adaptive sliding surface, which is added by a slider controller to a constant value of voltage in order to attain the MPPT. The small signal model slider controller takes current and voltage errors as inputs for regulating the solar voltage and currents. Based on solar radiation, the sliding surface is varied step by step using the adaptive MPPT technique.

Table 3. Slider controller design parameters

\begin{tabular}{l|c}
\hline Parameters & Values \\
\hline$C(s)$ & 1.000 \\
$K_{i}$ & 5.400 \\
$A$ & 0.200 \\
$\beta_{1}$ & 5.00 \\
$\beta_{2}$ & 0.10 \\
$\omega_{\mathrm{h}}$ & $10.0 \mathrm{rad} / \mathrm{sec}$ \\
$\omega$ & $100.0 \mathrm{rad} / \mathrm{sec}$ \\
$\Delta$ & 1.50 \\
\hline
\end{tabular}

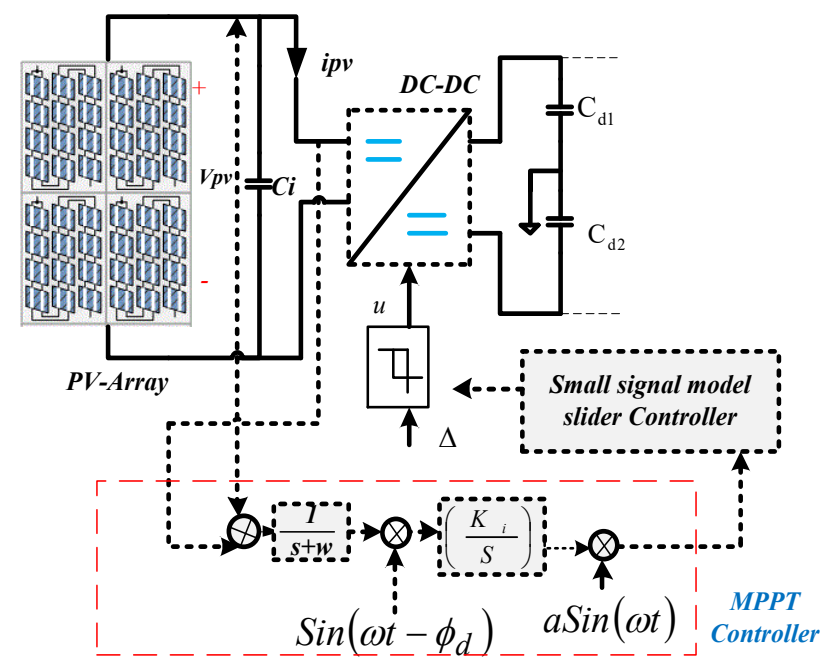

Fig. 4. Small signal model slider controller

\section{Design of TWO-LEG INVERTER}

The design description of two leg inverter topology is illustrated in Section-II. From the literature survey [22], the conventional three-leg VSI converts $\mathrm{dc}$-ac and it gives supply voltage to the grid. In the worst case, if anyone of the leg fails in the conventional inverter, the entire supply may get shut down. In order to overcome this issue, a two-leg inverter topology is used for the continuous power supply to the grid. From Fig.5, phase A supplies the line to line voltage of $E_{a}$ and phase $B$ supplies the line to line voltage of $E_{b}$. The RMS value of line to line voltages $\left(E_{a}, E_{b}\right)$ is equal to $E$. The inverter gives the phase voltages of $V_{\text {inv-a }}, V_{\text {inv-b }}$ and its corresponding phase currents are $\mathrm{I}_{\text {inv-a }}$ and $\mathrm{I}_{\text {inv-b. }}$. The filter $\left(\mathrm{L}_{\mathrm{f}}-\mathrm{C}_{\mathrm{f}}\right)$ is used to suppress the inverter output voltage and current ripples. From the article [1], the authors proposed the slider controller to generate the switching pulses to the inverter and it requires many sensors to sense the different state variables and references for each pulse generation and hence, it is more complex to control grid voltage and power factor. So, the slider controller is not popular for inverter operation. To overcome this a fuzzy logic PWM controller for two-leg VSI is proposed as shown in Fig.5. The mathematical modeling of the two-leg inverter [1] is as follows, 


$$
\begin{aligned}
& \frac{d I_{j}}{d t}=\frac{2}{3 L_{t f}}\left(E_{j}-2 R_{t f} I_{j}-V_{p j}-I_{k} R_{t f}\right)-I_{v} \\
& I_{v}=\frac{1}{3 L_{t f}}\left(E_{k}-2 R_{t f} I_{k}-V_{p k}-I_{j} R_{t f}\right) \\
& \frac{d I_{i n v j}}{d t}=\frac{1}{C_{s f}}\left(I_{j}+I_{i n v j}-I_{p j}\right)
\end{aligned}
$$

$$
\begin{aligned}
& \frac{d V_{c d 1}}{d t}=\frac{-1}{C_{d 1}}\left(u_{a} I_{i n v-a}+u_{b} I_{i n v-b}\right)+\frac{I_{m a g}(1-u)}{C_{d 1}(1+N)} \\
& \frac{d V_{c d 2}}{d t}=\frac{1}{C_{d 2}}\left(\left(1-u_{a}\right) I_{i n v-a}+\left(1-u_{b}\right) I_{i n v-b}\right)+\frac{I_{m a g}(1-u)}{C_{d 2}(1+N)}
\end{aligned}
$$

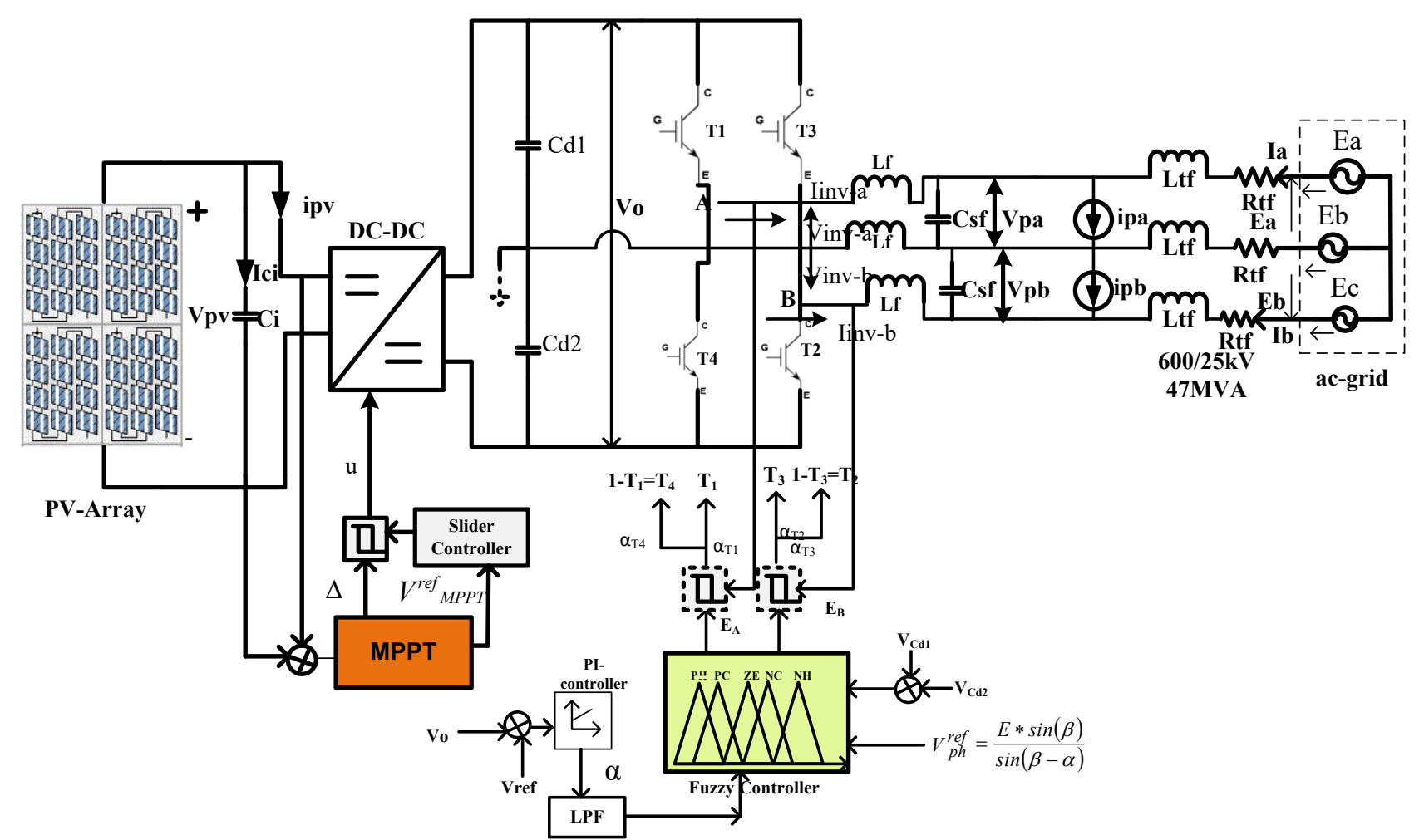

Fig. 5. FLC PWM controller-based two-leg three-phase inverter

Where the subscript indicates $j, K \in\{a, b\}$. The inverter dc-link voltages are given in equations (37) and (41). The principle operation of two-leg VSI is shown in Table.4. Here, when the switches $T_{1}$ and $T_{2}$ are in ON condition, then the voltage across the phase $\mathrm{A}$ and $\mathrm{B}$ are $\mathrm{V}_{\text {inv } \mathrm{a}}=\mathrm{V}_{0} / 2$, $\mathrm{V}_{\text {inv } \_}=-V_{0} / 2$ and $V_{\text {inv } \_c}=0$. Similarly, when the switches $T_{3}$ and $T_{4}$ are in $\mathrm{ON}$ condition, the voltage across phase $\mathrm{A}$ and $\mathrm{B}$ are $\mathrm{V}_{\text {inv } \_}=-\mathrm{V}_{0} / 2, \mathrm{~V}_{\text {inv }} \mathrm{b}=\mathrm{V}_{0} / 2$ and $\mathrm{V}_{\text {inv } \_}=0$. The switching angle of IGBT's $T_{1}$ and $T_{2}$ are $\alpha_{\mathrm{T} 1}$ and $\alpha_{\mathrm{T} 2}$. Similarly, the switching angle of IGBT's $T_{3}$ and $T_{4}$ are $\alpha_{\mathrm{T} 3}$ and $\alpha_{\mathrm{T} 4}$. The open delta connected phase voltages and phase currents of the load are expressed as $\mathrm{v}_{\mathrm{pa}}, \mathrm{v}_{\mathrm{pb}}, \mathrm{i}_{\mathrm{pa}}$, and $\mathrm{i}_{\mathrm{pb}}$.

In the fuzzy logic PWM controller, three operations are involved: fuzzification, inference mechanism, and defuzzification. The processes of converting input variables to linguistic functions are called fuzzification [23], [24]. The inference process controls the behavior of the surface related to the input and output variables and is defined by a set of rules which are given in Table.5. The final process, defuzzification, transforms the linguistic functions into crisp solutions before using it for a two-leg three-phase inverter. The main objective of fuzzy is to transfer maximum dc-dc converter output voltage through a two-leg inverter to the grid [9]. The major problem in solar power generation is the variation of the grid terminal voltage magnitude, which can be eliminated by the defuzzification technique.

The fuzzy rules are designed by using the error and change in error of converter dc-link voltage $\left(\mathrm{V}_{0}\right)$, grid RMS voltage $\left(\mathrm{V}_{\text {ref }}\right)$ and difference between the capacitor voltages $\left(\mathrm{V}_{\mathrm{dc} 1}, \mathrm{~V}_{\mathrm{dc} 2}\right)$. The maximum power is achieved by varying the modulation index of the DC-AC inverter based on input voltage and output voltage. These variables are fuzzified and are mentioned in the form of linguistic variables expressed by their membership functions which are predefined for every set. The membership function of the firing angle generation is given in Fig.6. The major advantage of the fuzzy logic PWM controller is that it doesn't consider mathematical equations and its process purely depends on a certain number of rules. The rules are expressed in five levels, namely Positive High (PH), Negative High $(\mathrm{NH})$, Positive Compact (PC), Negative Compact (NC) and Zero (ZE). The implementation of the fuzzy logic PWM controller is easy as compared to the slider PWM controller and it gives better performance over the years. The PWM pulses for the two-leg inverter is given in Fig.7. The contribution of applying the fuzzy PWM technique is to obtain balanced load voltage with high stability. In addition, it is used to get the unity power factor of load and grid. By applying a displacement angle ' $\alpha$ ', the maximum power of solar PV is transferred to the grid and local loads. The dc-link 
voltage $\left(\mathrm{V}_{0}\right)$ along with a PI controller is applied to the PWM controller in order to get the unity power factor. The displacement angle is derived as, $\mathrm{V}_{\mathrm{Ph}}$

Table 4. Switching operation of two-leg three-phase inverter

\begin{tabular}{c|c|c|c|c|c|c|c|c}
\hline \multicolumn{3}{c|}{ Nodes } & \multicolumn{4}{c|}{ Switching condition } & \multicolumn{3}{c}{ Inverter o/p voltage } \\
\hline $\mathrm{A}$ & $\mathrm{B}$ & $\mathrm{T}_{1}$ & $\mathrm{~T}_{2}$ & $\mathrm{~T}_{3}$ & $\mathrm{~T}_{4}$ & $\mathrm{~V}_{\text {inv a }}$ & $\mathrm{V}_{\text {inv }} \mathrm{b}$ & $\mathrm{V}_{\text {inv } \mathrm{c}}$ \\
\hline 0 & 0 & 0 & 1 & 0 & 1 & $-\mathrm{V}_{0} / 3$ & $-\mathrm{V}_{0} / 3$ & $2 \mathrm{~V}_{0} / 3$ \\
0 & 1 & 0 & 0 & 1 & 1 & $-\mathrm{V}_{0}$ & $\mathrm{~V}_{0}$ & 0 \\
1 & 0 & 1 & 1 & 0 & 0 & $\mathrm{~V}_{0}$ & $-\mathrm{V}_{0}$ & 0 \\
1 & 1 & 1 & 0 & 1 & 0 & $\mathrm{~V}_{0} / 3$ & $\mathrm{~V}_{0} / 3$ & $-2 \mathrm{~V}_{0} / 3$ \\
\hline
\end{tabular}

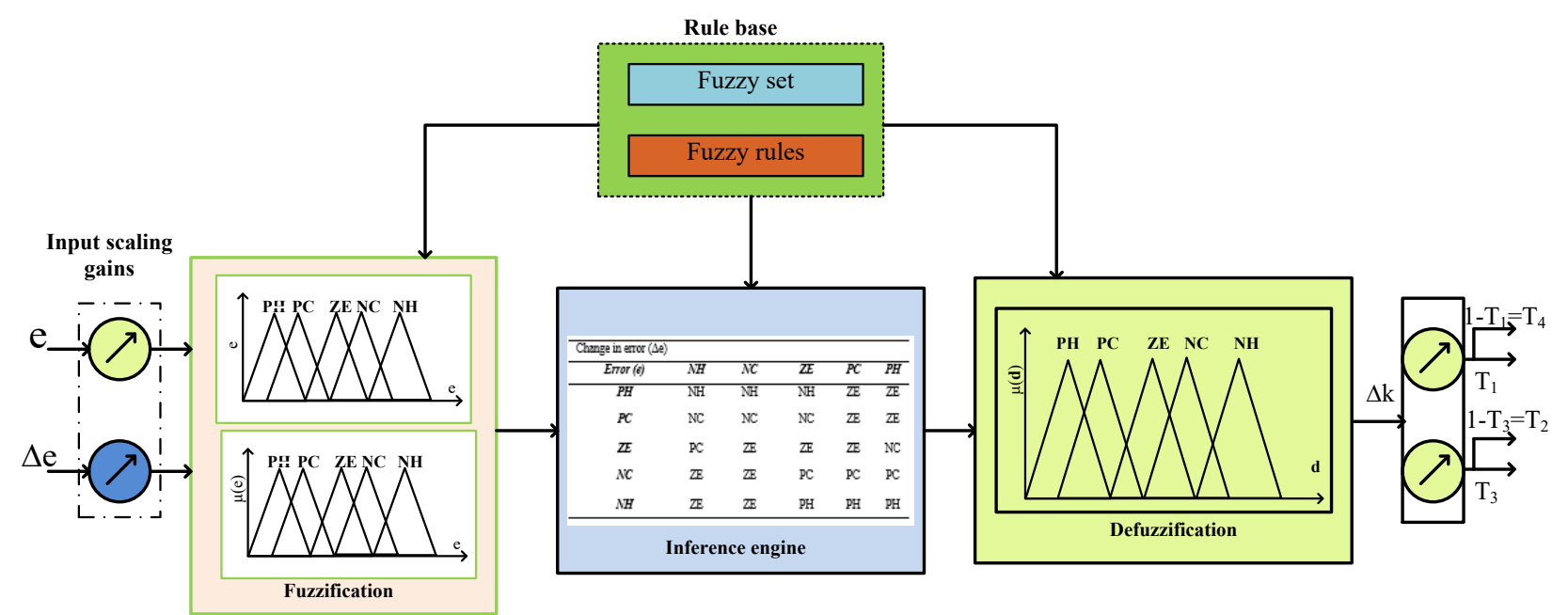

Fig.6. Fuzzy logic controller for two legs three-phase inverter

Table 5. Fuzzy rules for two-leg inverter PWM generation

\begin{tabular}{c|c|c|c|c|c}
\hline Change in error $(\Delta \mathrm{e})$ & \multicolumn{3}{|c}{} \\
\hline $\boldsymbol{E r r o r}(\boldsymbol{e})$ & $\boldsymbol{N H}$ & $\boldsymbol{N C}$ & $\boldsymbol{Z E}$ & $\boldsymbol{P C}$ & $\boldsymbol{P H}$ \\
\hline $\boldsymbol{P H}$ & $\mathrm{NH}$ & $\mathrm{NH}$ & $\mathrm{NH}$ & $\mathrm{ZE}$ & ZE \\
$\boldsymbol{P C}$ & $\mathrm{NC}$ & $\mathrm{NC}$ & $\mathrm{NC}$ & $\mathrm{ZE}$ & ZE \\
$\boldsymbol{Z E}$ & $\mathrm{PC}$ & $\mathrm{ZE}$ & $\mathrm{ZE}$ & $\mathrm{NC}$ \\
$\boldsymbol{N C}$ & $\mathrm{ZE}$ & $\mathrm{ZE}$ & $\mathrm{PC}$ & $\mathrm{PC}$ \\
$\boldsymbol{N H}$ & $\mathrm{ZE}$ & $\mathrm{ZE}$ & $\mathrm{PH}$ & $\mathrm{PH}$ & $\mathrm{PH}$ \\
\hline
\end{tabular}

$\alpha=K_{P}\left(V_{0}^{r e f}-V_{0}\right)+K_{i} \int\left(V_{0}^{r e f}-V_{0}\right) d t$

At grid side, the line to line RMS voltage is derived as,

$$
V_{p h}^{r e f}=\frac{E * \sin (\beta)}{\sin (\beta-\alpha)}
$$
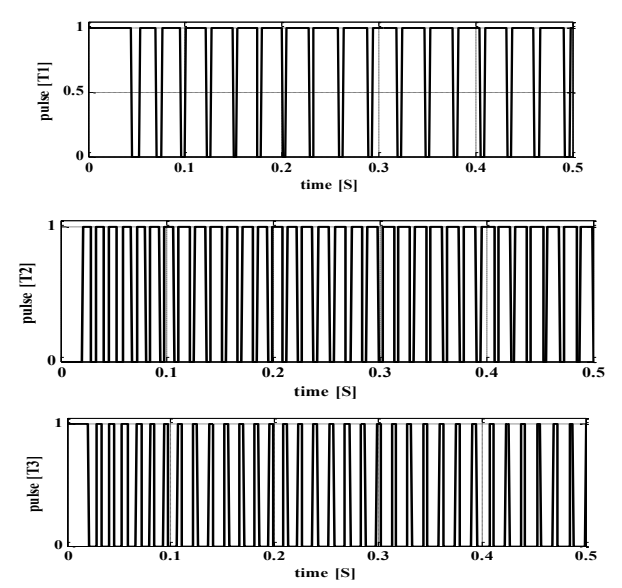

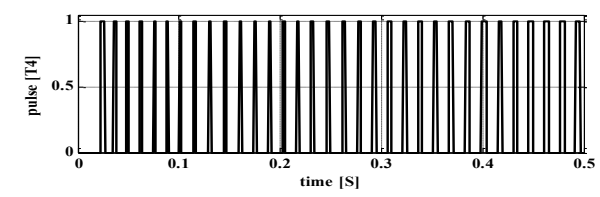

Fig.7. Switching pulses for two leg inverter

\section{Simulation results and discussion}

The nonlinear I-V and P-V characteristics of the solar panel (designed based on Table.1) are shown in Fig.8.

These characteristic curves are obtained with a single diode PV-module that is explained in Section-III at different irradiations $1000 \mathrm{~W} / \mathrm{m}^{2}, 750 \mathrm{~W} / \mathrm{m}^{2}$ and $500 \mathrm{~W} / \mathrm{m}^{2}$ respectively. From Fig.8 (a) and (b), the maximum power point is indicated at different irradiation levels. At 1000 $\mathrm{W} / \mathrm{m}^{2}$, the PV peak current and voltages are $23.33 \mathrm{~A}$ and $415 \mathrm{~V}$. Similarly, at $750 \mathrm{~W} / \mathrm{m}^{2}$ and $500 \mathrm{~W} / \mathrm{m}^{2}$, the PV peak currents and voltages are $16.82 \mathrm{~A}, 406 \mathrm{~V}$ and $12.89 \mathrm{~A}, 402 \mathrm{~V}$ respectively. The entire two-stage power conversion system is simulated and its performance is evaluated and demonstrated with different irradiation conditions as in Fig.9.

From Fig.9 at $1000 \mathrm{~W} / \mathrm{m}^{2}$, the PV power increases linearly up to $14 \mathrm{~ms}$ and after that, it is constant up to $4 \mathrm{~s}$. At 
$750 \mathrm{~W} / \mathrm{m}^{2}$ and $500 \mathrm{~W} / \mathrm{m}^{2}$, the step change in PV power occurs at 4.2 and $6.3 \mathrm{msec}$.
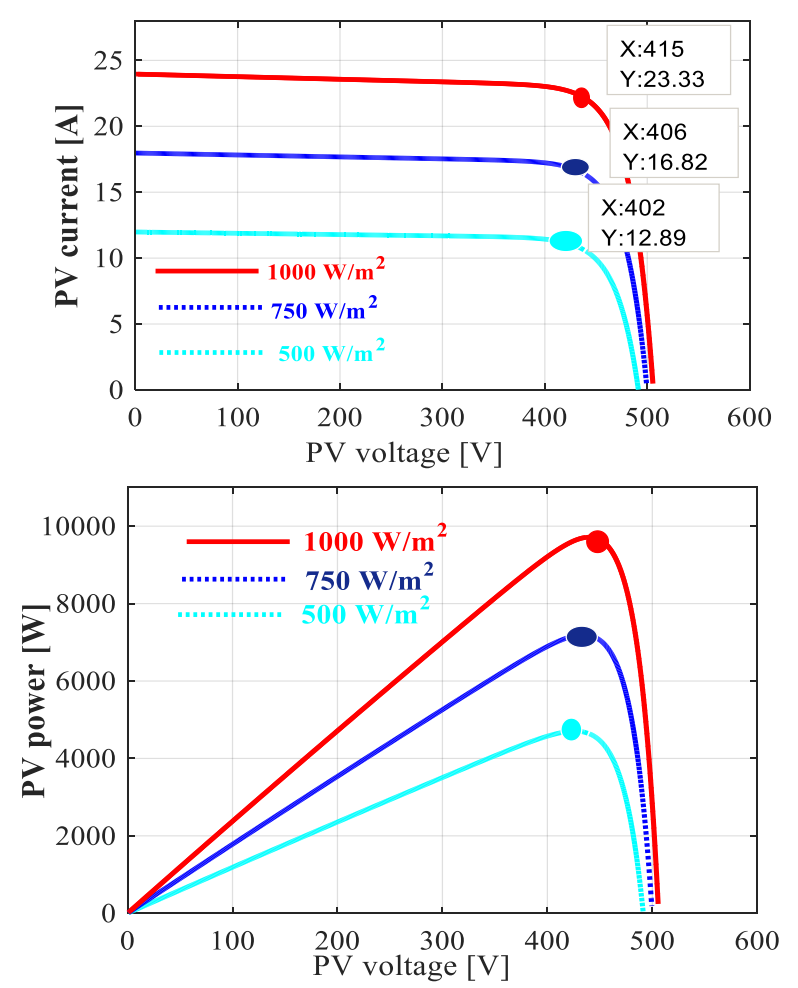

Fig. 8. (a) I-V curves at different irradiation levels $(1000,750$ and $500 \mathrm{~W} / \mathrm{m}^{2}$ ), (b) correlated P-V curves

Based on PV power variations, the adaptive slider controller tracks MPP with continuous variation of solar radiation. This MPPT technique gives a better dynamic performance with less oscillations and offers a better efficiency of around $97.8 \%$. Because of the input capacitor $\left(\mathrm{C}_{\mathrm{i}}\right)$ of the converter, the coupled inductor DC-DC converter steady-state output voltage ripples are negligible. The simulated DC-DC converter output voltage and its zoom view at $1000 \mathrm{~W} / \mathrm{m}^{2}$ is given in Fig. 10 .

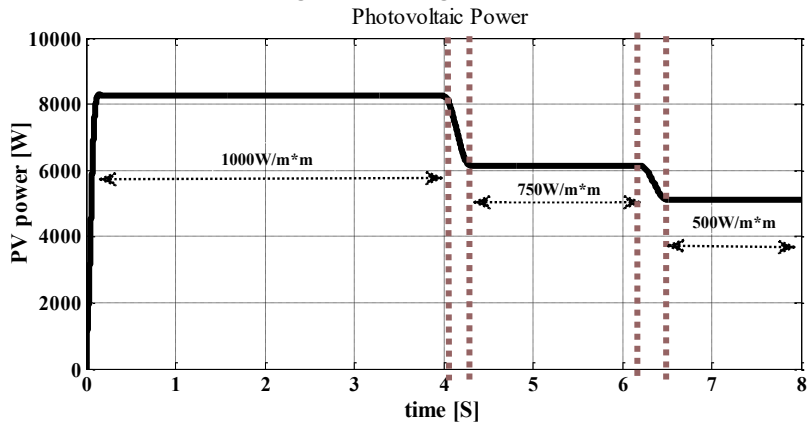

Fig. 9. PV power at variable irradiation condition $\left(1000 \mathrm{~W} / \mathrm{m}^{2}, 750\right.$ $\mathrm{W} / \mathrm{m}^{2}$ and $500 \mathrm{~W} / \mathrm{m}^{2}$ )

The DC-link capacitors are used to clamp the coupled inductor voltage ripples of the boost converter. The voltages of the DC-link capacitors are shown in Fig.11 and the corresponding zoom view gives the steady-state voltages at $1000 \mathrm{~W} / \mathrm{m}^{2}$. The inverter output of the $\mathrm{L}_{\mathrm{f}}-\mathrm{C}_{\mathrm{f}}$ filter is used to reduce THD of three-phase grid currents of the inverter which is shown in Fig. 12 and the zoom view gives steadystate grid currents at $1000 \mathrm{~W} / \mathrm{m}^{2}$.

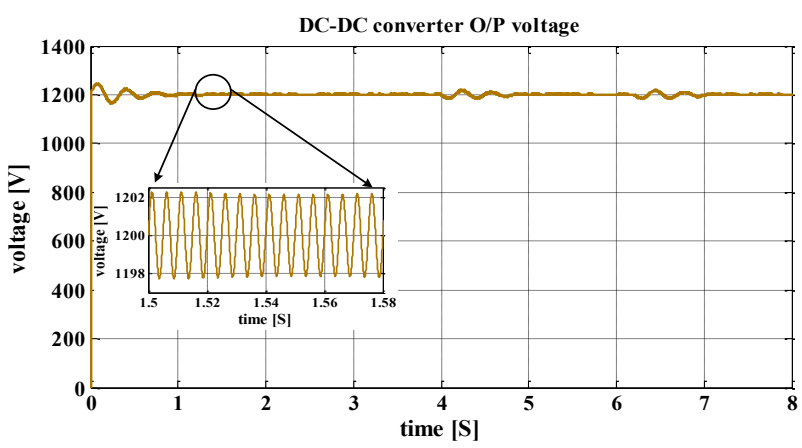

Fig. 10. DC-DC converter output voltage at different irradiations, 1000 $\mathrm{W} / \mathrm{m}^{2}, 750 \mathrm{~W} / \mathrm{m}^{2}$ and $500 \mathrm{~W} / \mathrm{m}^{2}$, (including zoom view at $1000 \mathrm{~W} / \mathrm{m}^{2}$ )

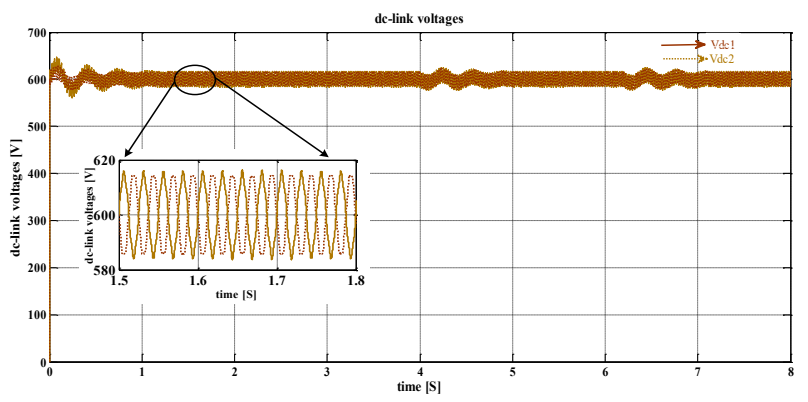

Fig. 11. DC-link capacitor voltages at different irradiation levels, 1000 $\mathrm{W} / \mathrm{m}^{2}, 750 \mathrm{~W} / \mathrm{m}^{2}$ and $500 \mathrm{~W} / \mathrm{m}^{2}$, (including zoom view at $1000 \mathrm{~W} / \mathrm{m}^{2}$ )

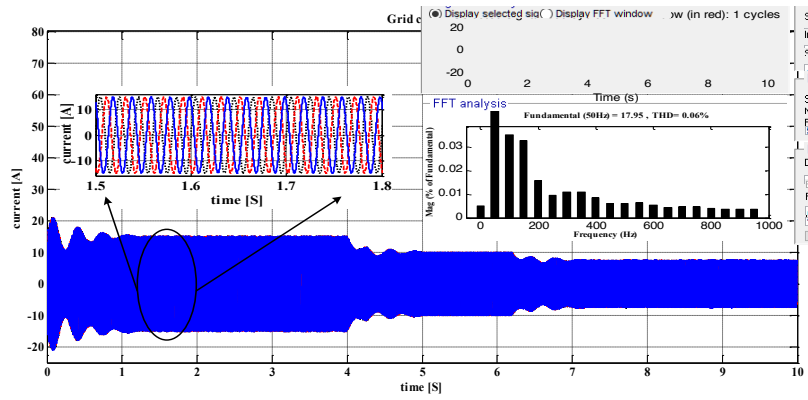

Fig. 12. Three-phase grid currents at different irradiation levels, 1000 $\mathrm{W} / \mathrm{m}^{2}, 750 \mathrm{~W} / \mathrm{m}^{2}$ and $500 \mathrm{~W} / \mathrm{m}^{2}$, (including zoom view at $1000 \mathrm{~W} / \mathrm{m}^{2}$ )
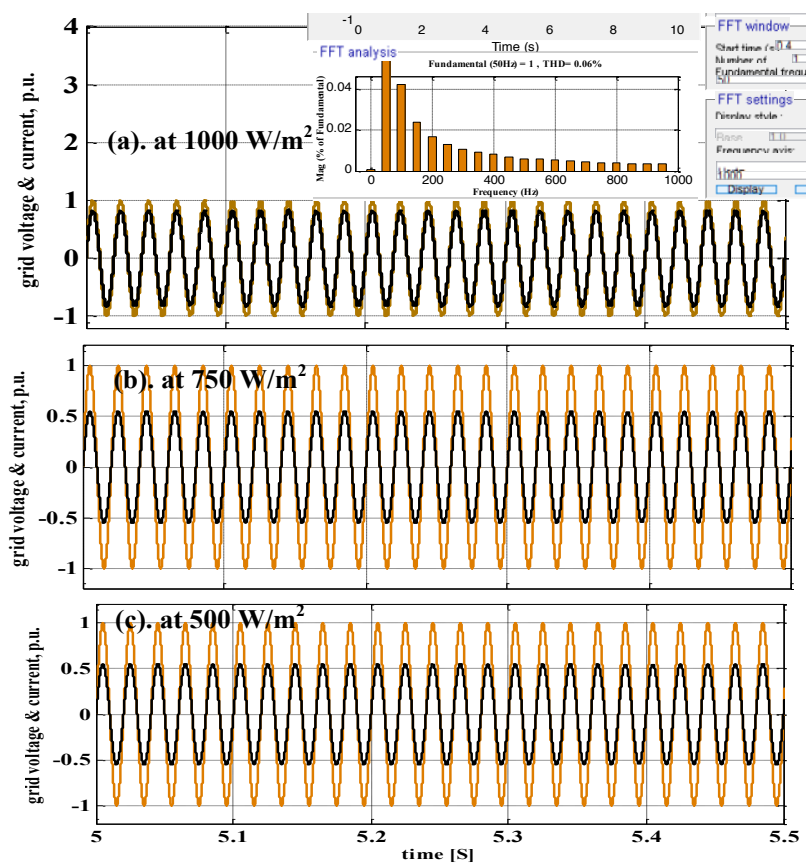

Fig. 13. Three-phase load (Grid) voltage and currents at different irradiation conditions, 1000,750 and $500 \mathrm{~W} / \mathrm{m}^{2}$ 
The performance of slider and fuzzy logic PWM control techniques is evaluated by considering the parameters such as efficiency, ICBC slider surface, the variation of modulation index of the inverter, THD and maximum power extraction. At $1000 \mathrm{~W} / \mathrm{m}^{2}$, the base and real value of the currents are $20 \mathrm{~A}$ and $16 \mathrm{~A}$. Similarly, the base and real value of voltage are $600 \mathrm{~V}$ and $580 \mathrm{~V}$. The simulated per unit grid current and voltages are shown in Fig.13 (a), (b) and (c) at different irradiation levels. In addition, the THD of grid voltage is included in Fig.13. From the results of three-phase voltages and currents, the system is operating with a unity power factor with zero voltage and current ripples. From all the simulated results and mathematical calculations, it is observed that the proposed solar power generation system is well suited to industrial as well as grid-connected applications.

\section{Conclusion}

The detailed proposed strategy is implemented in two stages. In stage one, a small signal model LPF based slider controller is implemented to improve the SSICBC voltage gain, maintaining the voltage balance between the PV and converter output at infinite switching control. In the second stage, a two-leg VSI used, in which the utilization of switches is reduced by two driver circuits to trigger the switches. Hence, in the inverter switching, conduction losses and size of the inverter reduces compare to conventional six switch inverter. The fuzzy logic PWM controller is used in the two-leg inverter to reduce system design complexity, load voltage imbalance and to maintain load at unity power factor. An adaptive MPPT is used to track the maximum power of the PV panel. Therefore, it is concluded that the fuzzy logic based two-leg three-phase inverter for solar PVgrid connected application will operate effectively and efficiently with high accuracy.

\section{Acknowledgment}

We would like to thanks to the University Grants Commission, Govt. of India (MANF-2017-18-AND-76098) for funding our research program and we especially thank VIT University management for providing all the facilities to carry out our research work.

This is an Open Access article distributed under the terms of the Creative Commons Attribution License.

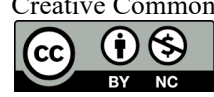

\section{References}

1. D. Lauria , and M. Coppola. "Design and control of an advanced PV inverter." Solar Energy 110 (2014): 533-542.

2. Yang,. Fei. "Discontinuous-Current Mode Operation of a TwoPhase Interleaved Boost DC-DC Converter With Coupled Inductor." IEEE Transactions on Power Electronics33.1 (2018): 188-198.

3. A. Christian, et al. "DC-DC MMC for HVdc Grid Interface of Utility-Scale Photovoltaic Conversion Systems." IEEE Transactions on Industrial Electronics 65.1 (2018): 352-362.

4. Ehsan, Teymoor Ghanbari.. "A model-based algorithm for maximum power point tracking of PV systems using exact analytical solution of single-diode equivalent model." Solar Energy 162 (2018): 117-131.

5. Basha, CH Hussaian, et al. "Mathematical Design and Analysis of Photovoltaic Cell Using MATLAB/Simulink." Soft Computing for Problem Solving. Springer, Singapore, 2020. 711-726.

6. Basha, CH Hussaian, C. Rani, and S. Odofin. "A review on nonisolated inductor coupled dc-dc converter for photovoltaic gridconnected applications." International Journal of Renewable Energy Research (IJRER) 7.4 (2017): 1570-1585.

7. Zih-Ming Li, and Ruey-Hsun Liang.. "A novel soft-switching interleaved coupled-inductor boost converter with only single auxiliary circuit." IEEE Transactions on Power Electronics 33.3 (2018): 2267-2281.

8. Basha, C. H., and C. Rani. "Different Conventional and Soft Computing MPPT Techniques for Solar PV Systems with High Step-Up Boost Converters: A Comprehensive Analysis." Energies 13.2 (2020): 371.

9. RAMASAMY, Sudha, and Damodhar REDDY. "Comparative Analysis of P \& O and RBFN MPPT Controller Based Three Level SEPIC Topology for $1.2 \mathrm{~kW}$ Solar PV System." Gazi University Journal of Science 32.3 (2019): 853-869.

10. Bertin, NZOUNDJA FAPI Claude, et al. "Real-Time Experimental Assessment of Hill Climbing MPPT Algorithm Enhanced by Estimating a Duty Cycle for PV System." International Journal of Renewable Energy Research (IJRER) 9.3 (2019): 1180-1189.

11. Alsumiri, Mohammed. "Residual Incremental Conductance Based Nonparametric MPPT Control for Solar Photovoltaic Energy Conversion System." IEEE Access 7 (2019): 87901-87906.

12. Pahari, Om Prakash, and Bidyadhar Subudhi. "Integral sliding mode-improved adaptive MPPT control scheme for suppressing grid current harmonics for PV system." IET Renewable Power Generation 12.16 (2018): 1904-1914.

13. Swamy, R. Linga, and R. Somanatham. "Analysis of CMV Reduction Methods for Three-Level NPC Inverter Fed Induction
Motor." Advances in Decision Sciences, Image Processing, Security and Computer Vision. Springer, Cham, 2020. 373-382.

14. Sahoo, Saroj Kumar, and Tanmoy Bhattacharya. "Phase-shifted carrier-based synchronized sinusoidal PWM techniques for a cascaded H-bridge multilevel inverter." IEEE Transactions on Power Electronics 33.1 (2017): 513-524.

15. Ariff, Engku Ahmad Rafiqi Engku, Obrad Dordevic, and Martin Jones. "A space vector PWM technique for a three-level symmetrical six-phase drive." IEEE Transactions on Industrial Electronics 64.11 (2017): 8396-8405.

16. Shanmugam, Sathishkumar, and Meenakumari Ramachandran. "Online UPS Inverter Controlled Using Soft Computing Techniques Modeling and Simulation." Water and Energy International 59.10 (2017): 32-38.

17. Tang, Guijian, et al. "An Improved MPP-Based Importance Sampling Method for Reliability Analysis." World Congress of Structural and Multidisciplinary Optimisation. Springer, Cham, 2017.

18. Amir, A., J. Selvaraj, and Nasrudin Abd Rahim. "Study of the MPP tracking algorithms: Focusing the numerical method techniques." Renewable and Sustainable Energy Reviews 62 (2016): 350-371.

19. Shukla, Akash Kumar, K. Sudhakar, and Prashant Baredar. "Design, simulation and economic analysis of standalone roof top solar PV system in India." Solar Energy 136 (2016): 437-449.

20. Umadevi, K., and C. Nagarajan. "Design and implementation of novel soft switching method based DC-DC converter with nonisolated coupled inductor in solar system using FPGA." Microprocessors and Microsystems 73 (2020): 102952.

21. Yin, Xiuxing, Zhansi Jiang, and Li Pan. "Recurrent neural network based adaptive integral sliding mode power maximization control for wind power systems." Renewable Energy 145 (2020): 11491157.

22. Ibrahim, Anas, and Muhamad Zahim Sujod. "Variable switching frequency hybrid PWM technique for switching loss reduction in a three-phase two-level voltage source inverter." Measurement 151 (2020): 107192.

23. Ferdaus, Md Meftahul, et al. "Pac: A novel self-adaptive neurofuzzy controller for micro aerial vehicles." Information Sciences 512 (2020): 481-505.

24. Azar, Ahmad Taher, et al. "Adaptive neural-fuzzy and backstepping controller for port-Hamiltonian systems." International Journal of Computer Applications in Technology 62.1 (2020): 1-12. 